\title{
PENGARUH STRATEGI PEMBELAJARAN PAILKEM DENGAN MEDIA ANIMASI TERHADAP HASIL BELAJAR IPA SISWA KELAS IV SDN 3 KEDUNGBANTENG TAHUN AJARAN 2015/2016.
}

\author{
Titik Suparminingsih \\ SDN 3 Kedungbanteng \\ dtryanasari@gmail.com
}

\begin{abstract}
Low student learning outcomes in science subjects is because teachers in the field using conventional learning strategies, so that students feel bored and not in the spirit of the learning process. Therefore, the teachers are required to be able to choose an effective learning strategies and efficient. This study aims to determine whether or not the influence of learning strategies PAILKEM with animated media for learning outcomes IPA grade IV SDN Kedungbanteng 3 City Ponorogo in academic year 2015/2016. This research is a quantitative research using experimental methods. This study research design static two groups. The sample selection using saturation sampling technique that is all class IVA and IVB with the number of 27 students per class. The data collection technique using the test method to learn science student outcome data. Data were analyzed with the average difference test (t-test) were previously performed tests of normality and homogeneity test. The results of t-test analysis showed that the value t_hitung $=3.098961$ and $\mathrm{t} \_$tabel $=1.703$ and significance level of 5\% t_hitung $>\mathrm{t}$ _tabel then $\mathrm{H} \_0$ rejected concluded that received $\mathrm{H} \_0 \mathrm{H} \_\mathrm{a}$ rejected and accepted. so it can be concluded that the learning outcomes of students in the class who were treated using learning strategies PAILKEM with animation media better than the class that is not treated with the use of learning strategies PAILKEM with animation media. This means that there is a significant effect on student learning outcomes with the application of learning strategies PAILKEM with animation media in science subjects subject matter "Natural Resources" in the fourth grade SDN Kedungbanteng 3 cities Ponorogo.
\end{abstract}

Keywords: Learning Outcomes, PAILKEM, Media Animation

\begin{abstract}
ABSTRAK
Hasil belajar siswa yang rendah pada mata pelajaran IPA disebabkan karena guru di lapangan menggunakan strategi pembelajaran yang konvensional, sehingga siswa merasa jenuh dan tidak semangat dalam mengikuti proses pembelajaran. Oleh sebab itu seorang guru dituntut untuk dapat memilih strategi pembelajaran yang efektif dan efisien. Penelitian ini bertujuan untuk mengetahui ada atau tidaknya pengaruh strategi pembelajaran PAILKEM dengan media animasi terhadap hasil belajar IPA siswa kelas IV SDN Kedungbanteng 3 Kota Ponorogo tahun pelajaran 2015/2016. Penelitian ini merupakan jenis penelitian kuantitatif yang menggunakan metode eksperimen. Penelitian ini menggunakan desain penelitian statis dua kelompok. Pemilihan sampel ini menggunakan teknik sampling jenuh yaitu semua kelas IVA dan IVB dengan jumlah 27 siswa setiap kelas. Teknik pengumpulan data menggunakan metode tes untuk data hasil belajar IPA siswa. Data yang diperoleh dianalisis dengan uji perbedaan rataan (uji-t) yang sebelumnya dilakukan uji normalitas dan uji homogenitas. Hasil analisis uji-t menunjukkan bahwa nilai $t_{\text {hitung }}$ $=3,098961$ dan $t_{\text {tabel }}=1,703$ dan taraf signifikansi 5\% $t_{\text {hitung }}>t_{\text {tabel }}$ maka $H_{0}$ ditolak disimpulkan bahwa diterima $H_{0}$ ditolak dan $H_{a}$ diterima. sehingga dapat disimpulkan bahwa hasil belajar siswa pada kelas yang diberi perlakuan menggunakan strategi pembelajaran PAILKEM dengan media animasi lebih baik dari pada kelas yang tidak diberi perlakuan dengan menggunakan strategi pembelajaran PAILKEM dengan media animasi. Artinya ada pengaruh yang signifikan terhadap hasil belajar siswa dengan penerapan strategi pembelajaran PAILKEM dengan media animasi pada mata pelajaran IPA materi pokok "Sumber Daya Alam" pada kelas IV SDN Kedungbanteng 3 kota Ponorogo.
\end{abstract}

Kata kunci: Hasil Belajar, PAILKEM, Media Animasi 


\section{A. PENDAHULUAN}

Berdasarkan hasil observasi dengan guru dan siswa kelas IV SDN 3 Kedungbanteng Salah satu mata pelajaran yang nilai hasil belajar siswa rendah adalah IPA. Permasalahan utama yang muncul di SD ini adalah siswa merasa bosan dan tidak fokus terhadap pembelajaran.

Berdasarkan ulasan permasalahan tersebut, peneliti tertarik untuk mengadakan penelitian di SDN 3 Kedungbanteng, dengan jumlah siswa kelas IV kurang lebih 54 siswa yang terdiri dari dua kelas yaitu kelas IVA sejumlah 27 siswa dan kelas IVB sejumlah 27 siswa. Di SDN 3 Kedungbanteng dalam mencapai indikator tertentu pada mata pelajaran IPA khusunya di kelas IV masih ditemukan siswa yang nilainya kurang memuaskan atau masih dibawah KKM. SDN 3 Kedungbanteng Ponorogo merupakan sekolah dasar yang masih tergolong rata-rata. Dari permasalahan di atas peneliti menggunakan strategi PAILKEM dengan media animasi untuk meningkatkan hasil belajar siswa mata pelajaran IPA kelas IV SDN 3 Kedungbanteng

PAILKEM merupakan sinonim dari pembelajaran Aktif, Inovatif, Lingkungan, Kreatif, Efektif, dan Menarik. PAILKEM merupakan salah satu strategi yang digunakan untuk mengoptimalkan proses pembelajaran. Strategi pembelajaran PAILKEM senantiasa memposisikan guru sebagai orang yang menciptakan suasana belajar yang kondusif atau sebagai fasilitator dalam belajar, sementara siswa sebagai peserta belajar yang harus aktif dan inovatif. Lingkungan dimanfaatkan sebagai sumber belajar yang kreatif, efektif, dan menarik. Strategi pembelajaran PAILKEM, didalam pelaksanaannya itu terjadi dialog yang interaktif antara siswa dengan siswa, siswa dengan guru atau siswa dengan sumber belajar lainnya. Siswa akan merasa tidak terbebani secara perseorangan dalam memecahkan masalah yang dihadapi dalam belajar, tetapi mereka dapat saling bertanya dan berdiskusi. Strategi pembelajaran tersebut akan berjalan secara optimal jika didukung 
Titik Suparminingsih: Pengaruh Strategi Pembelajaran... | 243

dengan menggunakan media pembelajaran yang menarik.

Media

pembelajaran

merupakan sarana atau alat terjadinya proses belajar mengajar.

Tersedianya media pembelajaran

dalam proses pembelajaran sangatlah

penting untuk memberikan gambaran

secara konkrit dan peserta didik akan

lebih mudah dalam memahami

materi yang diajarkan. Sehingga

akan menghidari adanya miskonsepsi

pada peserta didik. Peranan media

dalam dunia pendidikan sangatlah

banyak, diantaranya: (1) Mengindari

terjadinya verbalisme,

Membangkitkan minat dan motivasi peserta didik, (3) Menarik perhatian peserta didik, (4) Mengatasi keterbatasan ruang, waktu, dan ukuran, (5) Mengaktifkan peserta didik dalam kegiatan belajar mengajar, (6) Mengefektifkan pemberian rangsangan kepada peserta didik untuk belajar, (7) Menambah pengertian nyata suatu informasi. Perkembangan media pembelajaran tidak luput dari perkembangan ilmu pengetahuan dan teknologi, banyak kita ketahui tentang penggunaan media

pembelajaran yang telah menggunakan teknologi-teknologi modern, salah satunya computer yang menggunakan softwaresoftware yang bisa kita dapatkan dengan mudah. Software tersebut sangatlah bermanfaat serta menunjang untuk digunakan dalam proses pembelajaran. Software yang dapat digunakan untuk proses pembelajaran adalah program animasi Macromedia Flash Pro8. Program animasi Macromedia Flas Pro 8 memiliki kelebihan dari media animasi yang lain, keunggulan tersebut terletak pada adanya tombol interaktif dengan sebuah movie atau objek yang lain, dapat membuat perubahan transparasi warna dalam movie, dapat membuat animasi dari satu bentuk ke bentuk yang lain, dan dapat membuat gerakan animasi dengan mengikuti alur yang telah ditetapkan.

Dalam strategi PAILKEM guru dapat menjadi fasilitator yang baik yang dapat memberikan arahan atas kesulitan yang dihadapi siswanya. Strategi PAILKEM merupakan strategi pembelajaran yang memiliki tujuan untuk membangun proses 
244 | Premiere Educandum, Volume 6 Nomor 2, Desember 2016, 241 - 250

pembelajaran yang dinamis, ada di atas, dapat dirumuskan mengaktifkan siswa, masalah sebagai berikut : "Adakah mengkreaktifkan, mengefektifkan pengaruh penggunaan strategi dan menyenangkan bagi siswa dalam PAILKEM dengan media animasi berlangsungnya suatu proses pembelajaran. Siswa juga dituntut lebih aktif selama proses pembelajaran berlangsung.

Berdasarkan latar belakang di atas, maka dalam penelitian ini penulis akan meneliti pengaaruh strategi PIALKEM dengan media Animasi terhadap hasil belajar IPA siswa kelas IV SDN 3 Kedungbanteng Ponorogo tahun pelajaran 2015/2016.

Bertolak dari latar belakang masalah tersebut maka batasan dari penelitian ini adalah sebagai berikut :

1. Media pembelajaran yang digunakan adalah media animasi Macromedia Flash Pro 8.

2. Subjek Penelitian adalah siswa kelas IV SDN 3 Kedungbanteng Ponorogo Tahun Pelajaran 2015/2016.

3. Mata pelajaran yang diajarkan adalah IPA dengan materi sumber daya alam.

Berdasarkan dari latar belakang masalah dan batasan masalah yang terhadap hasil belajar IPA siswa kelas IV SDN 3 Kedungbanteng Ponorogo tahun pelajaran 2015/2016?"

Berdasarkan dari latar belakang masalah dan rumusan masalah, tujuan dari penelitian ini adalah untuk mengetahui Pengaruh Penggunaan Strategi PAILKEM dengan Media Animasi Terhadap Hasil Belajar IPA Siswa Kelas IV SDN 3 Kedungbanteng Ponorogo Tahun Pelajaran 2015/2016.

\section{B. METODE PENELITIAN}

Penelitian ini dilaksanakan di SDN 3 Kedungbanteng Ponorogo pada semester II tahun pelajaran 2015/2016. Kelas eksperimen dengan menggunakan strategi PAILKEM dengan media animasi, sedangkan kelas kontrol dengan menggunakan strategi konvensional tanpa menggunakan media pembelajaran.

Populasi dalam penelitian ini adalah semua siswa kelas IV semester II SDN 3 Kedungbanteng Ponorogo tahun pelajaran 2015/2016. 
Teknik pengambilan sampel homogenitas menggunakan uji F. dilakukan dengan cara pengambilan dengan taraf signifikansi $5 \%$.

sampel jenuh. Sampel dalam penelitian ini adalah kelas IVA yang berjumlah 27 siswa dan IVB yang berjumlah 27 siswa $\quad$ SDN 3 Kedungbanteng Ponorogo.

Variabel bebas dalam penelitian ini adalah strategi Pebelajaran PAILKEM dengan media animasi. Variabel terikat dalam penelitian ini adalah hasil belajar siswas mata pelajaran IPA. Teknik pengumpulan data menggunakan teknik dokumentasi dan tes.

Tes uji coba (try out) pada instrumen penelitian dilakukan untuk mengetahui validitas produk moment, reliabilitas, daya beda, dan taraf kesukaran butir soal.

Uji hipotesis dalam penelitian ini menggunakan uji-t ( $t$-test) yang didahului uji normalitas menggunakan uji lilliefours dan uji

\section{HASIL PENELITIAN}

Data hasil belajar dan penelitian diambil dari dua kelas yaitu kelas IVA yang berjumlah 27 siswa sebagai kelas eksperimen menggunakan strategi pembelajaran PAILKEM engan media animasi, dan kelas IVB yang berjumlah 27 siswa sebagai kelas kontrol yang menggunakan strategi konvesional tanpa menggunakan media pembelajaran.

Uji normalitas digunakan untuk mengetahui data yang diambil berasal dari populasi yang berdistribusi normal atau tidak. Uji normalitas dalam penelitian ini menggunakan metode lilliefors untuk mencapai $L_{\text {maks }}$ dari nilai tes IPA kelas IVA SDN 3 Kedungbanteng Ponorogo yang berjumlah 27 siswa dan kelas IVB SDN 3 Kedungbanteng Ponorogo yang berjumlah 27 siswa. 
246 | Premiere Educandum, Volume 6 Nomor 2, Desember 2016, 241 - 250

Tabel 1. Uji Normalitas Hasil Belajar

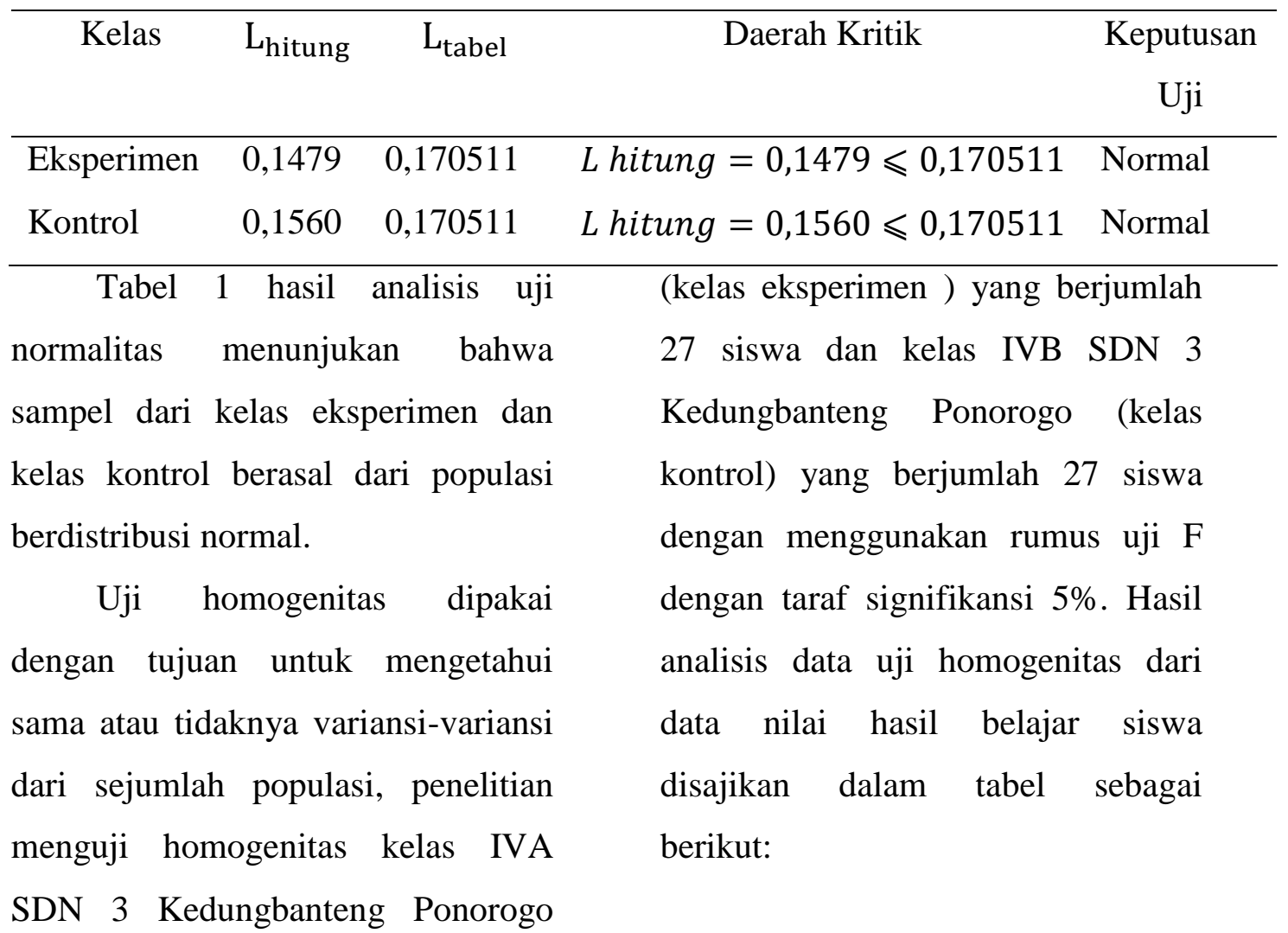

Tabel 2 Uji Homogenitas Hasil Belajar

\begin{tabular}{|c|c|c|c|}
\hline Uji Homogenitas & $F_{\text {hitung }}$ & $F_{\text {tabel }}$ & Kriteria \\
\hline Kontrol dan Eksperimen & 1,0757 & 1,9292 & Homogen \\
\hline
\end{tabular}

disimpulkan bahwa sampel dari kelas siswa.

eksperimen yang berjumlah 27

Uji hipotesis pada penelitian siswa dan kontrol yang berjumlah 27 ini menggunakan uji t dengan varian siswa berasal dari populasi yang homogen dan tingkat signifikansi 5\% memiliki variansi homogen. Uji Hipotesis yang digunakan dalam penelitian ini adalah uji t. uji $t$ digunakan untuk mengetahui adapun keputusan ujinya adalah sebagai berikut :

Dari hasil analisis diketahui perbedaan hasil belajar siswa yang bahwa nilai $t_{\text {hitung }}$ yang diperoleh adalah 3,098961 dengan $\alpha=0,05$, diperoleh dari kelas eksperimen dan artinya 3,098961 > 1,703 maka $\mathrm{H}_{0}$ ditolak disimpulkan bahwa $\mathrm{H}_{0}$ 
ditolak dan $\mathrm{H}_{1}$ diterima. Jadi, ada pengaruh penggunaan strategi PAILKEM dengan media animasi terhadap hasil belajar IPA siswa kelas IV SDN KEDUNGBANTENG 3 Kota Ponorogo tahun pelajaran 2015/2016.

\section{PEMBAHASAN}

Pada saat melakukan penelitian dilapangan yakni di SDN 3 Kedungbanteng Ponorogo peneliti mengambil nilai hasil belajar IPA kelas IV, kemudian nilai hasil belajar tersebut diuji dengan menggunakan rumus uji $\mathrm{t}$ peneliti mendapatkan hasil sebagai berikut :

\section{Hasil belajar IPA siswa dengan menggunakan strategi pembelajaran PAILKEM dengan media animasi}

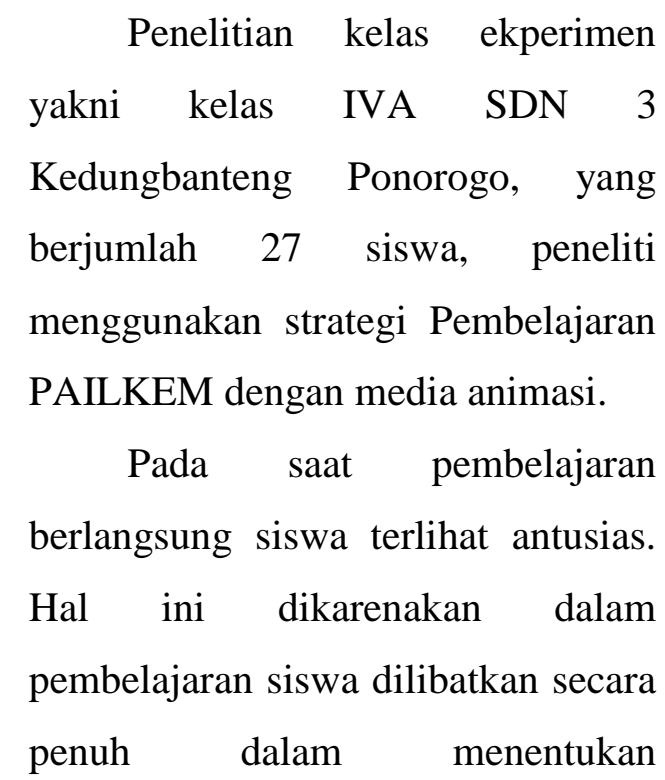

pengetahuan, dan mengaktifkan siswa untuk melakukan aktivitas belajar yang sesungguhnya, sehingga siswa lebih bersemangat dalam mengikuti proses pembelajaran.

Model pembelajaran ini juga memiliki tujuan yaitu untuk membangun proses pembelajaran yang dinamis, mengaktifkan siswa, mengkreaktifkan, mengefektifkan dan menyenangkan bagi siswa dalam berlangsungnya suatu proses pembelajaran. Siswa juga dituntut lebih aktif selama proses pembelajaran berlangsung.

Setelah proses pembelajaran selesai, dilakukan tes hasil belajar IPA untuk melihat tingkat keberhasilan belajar siswa. Hasil penghitungan tes hasil belajar IPA siswa diperoleh nilai rata-rata sebesar 90,33. Sehingga dapat disimpulkan hasil belajar siswa pada mata pelajaran IPA dengan menggunakan strategi PAILKEM dengan media animasi dikatakan tinggi.

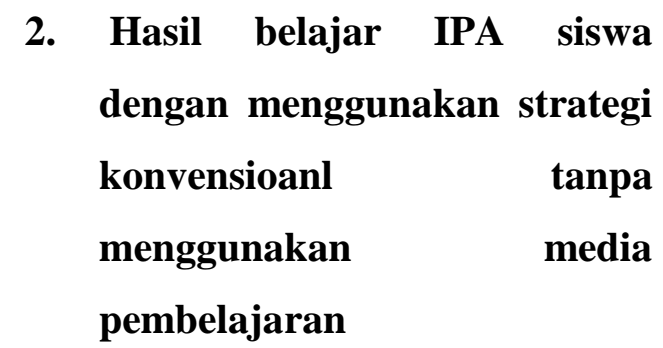


Dalam penelitian kelas eksperimen yakni siswa kelas IV SDN 3 Kedungbanteng Ponorogo, peneliti menggunakan strategi konvensioanl tanpa menggunakan media pembelajaran. Pada saat proses pembelajaran berlangsung, siswa tidak terlalu fokus dalam mengikuti pembelajaran. Siswa kurng antusias terdap maateri yang disampaikan. Siswa merasa lebih cepat bosan dan tentunya mempengaruhi kualitas belajarnya. Hal ini tentunya akan membuat hasil belajar siswa menjadi lebih rendah.

Setelah proses pembelajaran, dilakukan tes hasil belajar IPA untuk melihat tingkat keberhasilan belajar siswa. Hasil penghitungan tes hasil belajar IPA siswa diperoleh nilai rata-rata sebesar 74,44. Sehingga dapat disimpulkan hasil belajar siswa pada mata pelajaran IPA dengan menggunakan strategi pembelajaran konvensional tanpa menggunakan media pembelajaran dikatakan sedang.

\section{Perbandingan hasil belajar IPA siswa kelas eksperimen dan kelas kontrol}

Berdasarkan hasil uji hipotesis yang telah dilakukan dapat diketahui bahwa $t_{\text {hitung }}=3,098961$ dan $t_{\text {tabel }}$ $=1,703$ sehingga dapat disimpulkan bahwa penggunaan pendekatan pembelajaran berpengaruh terhadap hasil belajar IPA dengan taraf signifikan $5 \%$ atau 0,05 . Hal ini semakin diperkuat dengan hasil belajar yang diperoleh pada kelas eksperimen dan kelas kontrol, yaitu untuk kelas eksperimen dengan jumlah siswa 27 anak memiliki nilai rata-rata 90,33. Sedangkan kelas kontrol dengan jumlah siswa sama dengan kelas eksperimen yakni 27 anak memiliki nilai rata-rata 74,44 . Berdasarkan data tersebut, kelas eksperimen yang diajarkan dengan menggunakan strategi PAILKEM dengan media animasi memiliki ratarata yang lebih baik bila dibandingkan dengan kelas kontrol yang diajarkan dengan menggunakanstrategi konvensional tanpa menggunakan media pembelajaran.

\section{E. SIMPULAN DAN SARAN}

\section{Kesimpulan}

$$
\text { Hasil penelitian dan }
$$
pembahasan dalam penelitian ini, 
dapat disimpulkan bahwa ada perbedaan yang signifikan antara hasil belajar IPA siswa Kelas IVA SDN 3 Kedungbanteng Ponorogo yang menggunakan strategi pembelajaran PAILKEM dengan media animasi dan siswa kelas IVB SDN 3 Kedungbanteng Ponorogo yang menggunakan strategi konvensional tanpa menggunakan media pembelajaran. Hal ini dikarenakan hasil perhitungan uji-t yang diperoleh adalah $t_{\text {hitung }}=$ $3,098961>t_{\text {tabel }}=1,703$. Dengan demikian, hasil belajar IPA siswa Kelas IVA SDN 3 Kedungbanteng Ponorogo yang menggunakan strategi pembelajaran PAILKEM dengan media animasi lebih baik dibandingkan dengan hasil belajar siswa kelas IVB yang hanya menggunakan strategi konvensional tanpa menggunakan media pembelajaran.

\section{Saran}

Untuk meningkatkan hasil pembelajaran yang lebih baik lagi khususnya pada mata pelajaran IPA, maka peneliti dapat memberikan sedikit saran untuk meningkatkan suatu pembelajaran yang lebih menarik dan berkualitas lagi diantaranya adalah :

\section{Bagi Sekolah}

a. Sekolah diharapkan untuk melakukan sosialisasi kepada seluruh guru kelas yaitu untuk menggunakan dan meningkatkan model dan media yang sangat menarik pada saat pembelajaran berlangsung supaya siswa-siswi memiliki minat yang sangat tinggai untuk belajar atau memahami materi yang diajarkan oleh guru.

b. Sekolah diharapkan untuk selalu mendukung dan mengembangkan berbagai inovasi

\section{Bagi Guru}

a. Dalam melaksanakan suatu proses pembelajaran yang berlangsung sebaiknya guru selalu menggunakan model pembelajaran yang jelas sesuai dengan langkah-langkah yang telah ditetapkan.

b. Sebelum melaksanakan proses pembelajran berlangsung guru harus mempersiapkan terlebih dahulu materi, media dan lain-lain agar siswa lebih antusias dalam pembelajaran. 
250 | Premiere Educandum, Volume 6 Nomor 2, Desember 2016, 241 - 250

c. Guru sebaiknya memberikan reword atau nilai tambahan kepada siswa yang aktif. Agar siswa memiliki semangat belajar yang lebih tinggi.

d. Guru sebaiknya memberikan punisment kepada siswa yang ramai atau berperilaku menyimpang pada saat proses pembelajaran berlangsung.

e. Guru sebaiknya memanfaatkan alat-alat yang sudah diberikan pemerintah untuk fasilitas berlangsungnya suatu pembelajaran.

\section{Bagi Orang Tua}

Orang tua sebaiknya selalu memberi motivasi dan mendukung aktifitas belajar putra-putrinya di rumah demi kelangsungan proses belajarnya di sekolah.

\section{DAFTAR RUJUKAN}

Asmani. 2011. Tips Menjadi Guru Inspiratif, Kreatif, dan Inovatif. Yogjakarta: DIVA Press

Jihad, A dan Haris, A. 2008. Evaluasi Pembelajaran. Yogyakarta: Multi Pressindo.

Purwanto. (2011). Evaluasi Hasil Belajar. Yogyakarta: Pustaka Belajar.

Suryani, N dan Agung, L. 2012. Strategi Belajar Mengajar. Yogyakarta: Ombak.

Susanto, A. (2013). Teori Belajar dan Pembelajaran di Sekolah Dasar. Jakarta: Kencana.

Uno, Hamzah B. \& Mohamad, N. 2012. Belajar dengan Pendekatan PAILKEM. Jakarta: Bumi Aksara. 